\title{
Issues in Malaria Communication in Enugu, Southeast Nigeria
}

\section{Chinwe C. Okpoko}

Department of Mass Communication, University of Nigeria, Nsukka, Enugu State, Nigeria

Corresponding Author Email: chinwe.okpoko@unn.edu.ng

Elias C. Aniwada

Department of Community Medicine, University of Nigeria,

Enugu Campus, Enugu State, Nigeria Email: elias.aniwada@unn.edu.ng

Doi:10.5901/mjss.2017.v8n1p285

\section{Abstract}

Communication plays an important part in health promotion. Malaria affects millions of people worldwide, and is a major health challenge in Africa. This study seeks to determine the health communication interventions so far used on malaria, find out what has been achieved and suggest the way forward. The study adopted a descriptive survey design, along with documents to address the subject matter. The target population consists of all the people in Enugu metropolis with study population comprising healthcare providers, patients and the general public drawn from Enugu metropolis. Purposive sampling technique was employed in the selection of 130 respondents that were studied. Questionnaire was used for data collection. Descriptive statistics and chi-square test of independence were used to analyze the data. About $93.8 \%$ of the respondents were aware of the interventions on malaria. They have a good knowledge of available interventions on malaria: ITNs (86.2\%), IRS (51\%), and IPT (20\%). The distribution of media friendly intervention was highest for ITN, (47.6\%) followed by IRS (26.7\%). Also IPT are not only rarely (29.6\%) aired and /or received, but also never (30.3\%) publicized or received. Interventions on malaria were not independent of mass media interventions ( $p=0.007)$ while the degree of awareness of malaria is independent on the communication avenues $(p=0.378)$. Health interventions and policy framework to address malaria in Nigeria are available. However, there is need for audience-specific communication and attitudinal change to ensure improved uptake.

Keywords: Communication, Health intervention, Malaria, Mass media

\section{Introduction}

Communication is an integral aspect of interventions that seek to address individual, community and social factors and can have a significant impact on many levels of health intervention implementation. It is a transactional process, which in health context plays an important part in health promotion (Corcoran, 2007, p.6). Communication is extremely important in the fight against Malaria not only because it offers considerable instrumental value, but also because it facilitates access to interventions that aid the prevention, treatment and care for the ailment. It will also reduce vulnerability to the disease, improve advocacy, and subsequently enhance mobilization and networking. Mass media of communication has been a force that exerts great influence on the society. It is not only a dragon powerful tool used to send messages to wider public, but also an important tool that can shape people's perspectives and views on diverse issues in the society. The media represent a key component in the machinery of any campaign to create social awareness and mobilise people for action. This explains why various countries and bodies attempting to improve the health care system of their various constituencies involve communication.

In Nigeria, the federal government has recognised the contributions of health communication in health care delivery. It is seen as fundamental for equipping the public with the tools and knowledge required to respond appropriately to health crises such as flu outbreaks, HIVIAIDS, malaria etc (Health Communication online course, 2013). It is against this backdrop that most government, especially in developing countries like Nigeria, have come out with different development agenda to enhance the quality of life for her citizens. One of the major areas where such effort is being channeled in Nigeria is malaria that has since become a major health challenge.

World Health Organization's document entitled "World Malaria Report" (2015), notes that there were an estimated 438000 malaria deaths worldwide and that $90 \%$ of these deaths occurred in the African Region, including Nigeria. 
Malaria affects millions of people worldwide, but it is endemic mainly in Sub-Saharan Africa (Ogundipe and Obinna, 2010). Malaria is therefore a major health challenge in Africa. It is on record that Nigeria has more reported cases of malaria and deaths more than any other country in the world (Nigeria Malaria Fact Sheet in Ebong et al (2014). Women and children are the most adversely affected with over 90\% occurring in underdeveloped countries. The 2005 United Nations report notes that: Malaria [and Tuberculosis] has continued to rampage the endemic regions of sub-Saharan Africa. Despite various declarations by African governments in the 1990s and complementary effort promised in the main contents of the MDGs target, the disease still remains a menace and the economic impact resulting from its burden is overwhelming.

Malaria is responsible for $60 \%$ outpatient visits to health facilities, $30 \%$ childhood death, $25 \%$ of death in children under one year and 11\% maternal death in the country (National Malaria Control Program NMCP, 2008). An estimated 250,000 children under the age of five die every year in Nigeria due to the disease(UNICEF, 2009) and accounts for an average of 300,000 deaths a year (MDG, 2010 and Jimoh, et al, 2007).It currently accounts for nearly 110 million clinically diagnosed cases per year and 30 percent of hospitalizations. Nigeria bears about a quarter of the disease's burden in Africa, including a significant number of the one million lives lost per year in the region, particularly amongst children and pregnant women (Jimoh, et al, 2007). About 132 billion Naira (NMCP, 2008) or about $\$ 879$ million(USAID, 2010) in form of treatment costs, prevention, man-hours etc is lost annually in financial terms to this treatable and completely evitable disease (Amajor, 2011). It is however difficult to say categorically the magnitude of the problem and how it is changing through time, because the people have become so used to malaria that many of those who become sick with the ailment do not visit health care facilities and are therefore not captured in the available statistics (Jimoh, et al, 2007). Beyond the health dimension, malaria leaves untold social and economic consequences on people and nations alike. It causes great misery to sufferers, and adversely affects the social and psychological well-being of individuals, families and the nation at large (Amodu et al, 1998).

Both behavioural and non-behavioural factors account for the prevalence of malaria in Nigeria. Some cultural practices, which promote mosquito breeding and mosquitoes' access to the people, and the failure of at risk populations to use technologies required for effective treatment, control and prevention of malaria promptly and appropriately etc. have been implicated for the continued prevalence of malaria in these parts (FMOH, 2008). Added to the list is "lack of political will and commitment, poor perception of the magnitude of the malaria burden and poor treatment seeking behaviours of individuals and communities" (NMCP, 2008, p.6). The problem became more aggravated following the evolution of the parasites and vectors that are resistant to medicines and insecticides (NMCP, 2008, p.6). The geographical or ecological conditions of our region have been advanced as being very conducive for mosquitoes and the subsequent presence of plasmodia. It is therefore pertinent to understand the dynamics and implications of these factors to enable us design appropriate intervention programmes for tackling malaria in Nigeria (FMOH, 2008).

A systematic review of articles on barriers to the effective treatment and prevention of malaria in Africa over three decades by Maslove et al (2009), revealed that lack of understanding of the cause and transmission of malaria constitutes the most critical barrier to malaria prevention (74.4\%), followed by reports on the use of ineffective prevention measures (30.8\%), and the belief that malaria cannot be prevented (17.9\%). They also noted that the belief that a child with convulsion could die if given an injection or taken to hospital (25.6\%), is a major barrier to the treatment of childhood malaria.Indeed, and as reported by Maslove et al (2009), any successful effort at prevention and treatment of malaria in Africa must take cognizance of the overall social and cultural contexts, namely their values, belief systems and norms. This is where communication intervention becomes intrinsically very relevant to enable us educate them on the causative factors of malaria, as well as the treatment regimens.

It is argued that home management of malaria along with public information and Pre-Packaged Drugs (PPDs) can help to reduce malaria morbidity and mortality in children. The PPDs ensure that full treatment course is taken by patients and at the right time. Other initiatives used to combat the disease in the communities are: Role Model Mothers, use of Patent Medicine Vendors (PMVs) and other Community Health Volunteers (NMCP, 2008, p.32). Furthermore, Nigeria in collaboration with other African countries signed the Declaration and Plan of Action in 2000 to reduce the burden of the disease by half in the year 2010. Among the actions identified are: prompt diagnosis and treatment with effective medicines, distribution of insecticide-treated nets (ITNs) to achieve coverage of populations at risk (especially children under age five and pregnant women), indoor residual spraying (IRS) to curtail transmission, and prevention of malaria in pregnancy through intermittent preventive treatment (IPT) (NPC, NMCP, and ICF International, 2012, p.4).

A number of communication avenues through which malaria has either been prevented, treated or controlled have been identified by Ebong et al (2015). Among them are seminars, community outreach events and radio talk shows. These avenues aim essentially at encouraging communities to comply with instructions during IRS campaigns and to take personal protective measures against being bitten by malaria-infected mosqitoes. It is instructive to note that two strategic 
plans have been adopted to control the scourge of malaria in Nigeria since the beginning of this decade. The first covers the period 2001-2005, while the second covers the period 2006-2010. Nevertheless, in response to the new global direction on malaria control, the latter was revised in 2008 to cover the 2009-2013 periods. The aim is to scale up the interventions to accommodate not just the biologically vulnerable groups such as pregnant women and children, as outlined in the earlier plan, but also all at risk populations. The overall goal is to reduce by half the morbidity and mortality attributed to malaria in Nigeria by 2013 and to minimize its socioeconomic effects (NPC, NMCP, and ICF International, 2012, p.4).It must be stressed here that the Roll Back Malaria (RBM) programme is very strategic in the treatment of malaria in Nigeria. This is because its interventions are not only comprehensive, but also target all the populations at risk of malaria. They include: prompt and Effective Case Management, Intermittent Preventive Treatment of malaria in pregnancy, and Integrated Vector Management including the use of Insecticide Treated Nets (ITNS), Indoor Residual Spraying (IRS) and Environmental Management (Amajor, 2011).

The efforts so far made in Nigeria to curb the menace of malaria, particularly policy and plan initiation, appear commendable. However, there seem to be a wide gap between such policies/plans and their implementation. This is because the ailment has continued to be a major health issue in the country despite the huge resources, human and material, injected in the project. Hence, the need to address the issues that impede the success of the various plans of action and keep people more informed about the way out, using strategic communication, has become increasingly apparent. It is worthy to note that to be successful, many malaria control efforts require community participation, which in turn depends on individuals' knowledge and awareness of the disease (Dhawan et al, 2014).

It must be stressed that the main contents of the control program revolve around advocacy, behavior change communication and social mobilization. In essence, the strategic frameworks for malaria communication have been developed to ensure adequate awareness and utilization of interventions in Nigeria. Given the above scenario, therefore, one is inclined to ask if media awareness messages or campaigns against the disease are not properly communicated to Nigerians. Furthermore, how do we improve the process of healthcare delivery on malaria using the media of communication? Consequently, this study seeks to examine the awareness and knowledge of health interventions so far used on malaria in Nigeria, evaluate the effectiveness or otherwise of media interventions, and subsequently determine the way forward.

\section{Materials and Methods}

The study was conducted in Enugu the capital of Enugu State, Southeastern Nigeria. The city had a population of 717,291 according to the 2006 Nigerian census (FRN 2009).

Descriptive survey design was used in the research, which according to Kelley et al (2003) is well suited for studies of health and health services. It is usually done by means of a questionnaire or interview.

The study population comprised healthcare providers, patients and the general public drawn from Enugu city. Purposive sampling technique was employed in the selection of the respondents that were studied. The data were gathered using interviewer administered questionnaire meant to determine the awareness and/or understanding of Nigerians as regards communication and health interventions on malaria. Face-to-face interview was equally used to elicit information from patent medicine vendors, Disease Surveillance and Notification Officers and staff of ministry of health (malaria unit). Using sample size calculator for the survey system (www.surveysystem.com/sscalc.htm), with confidence level of $95 \%$ and margin of error of 5\%, the calculated sample size was 119 . However, a sample size of 130 was used for the study.

\section{Results}

Table 1: Socio-demographics of respondents Variable

\begin{tabular}{|c|c|c|}
\hline Age groups & Frequency & Percentage \\
\hline$\leq 30$ & 45 & 34.6 \\
\hline $31-40$ & 54 & 41.5 \\
\hline $41-50$ & 22 & 16.9 \\
\hline$>50$ & 9 & 7.0 \\
\hline Sex & & \\
\hline Male & 57 & 43.8 \\
\hline Female & 73 & 56.2 \\
\hline
\end{tabular}




\begin{tabular}{|c|c|c|}
\hline Marital status & & \\
\hline Married & 68 & 52.3 \\
\hline Single & 53 & 40.7 \\
\hline Divorced & 3 & 2.3 \\
\hline Widowed & 4 & 3.1 \\
\hline Separated & 2 & 1.6 \\
\hline Educational level & & 7 \\
\hline Primary & 9 & 22 \\
\hline Secondary & 29 & 67 \\
\hline Tertiary & 87 & 4 \\
\hline Others & 5 & 58.5 \\
\hline Employment status & & 13 \\
\hline Employed & 76 & 14 \\
\hline Self-employed & 17 & 13 \\
\hline Unemployed & 18 & 1.5 \\
\hline Student & 17 & \\
\hline Others & 2 & \\
\hline & & \\
\hline & & \\
\hline
\end{tabular}

A greater percentage of respondents (41.5\%) fall between the age range of 31 and 40 years. They were mainly females (56.2\%), highly educated as $67 \%$ of them attended tertiary institutions while $22 \%$ had secondary education. About $52.3 \%$ were married and $58.5 \%$ employed.

Table 2: Respondents' awareness and knowledge of health interventions for malaria

\begin{tabular}{|l|c|c|}
\hline \multirow{2}{*}{ Variables } & \multicolumn{2}{|c|}{$\mathrm{n}=130$} \\
\cline { 2 - 3 } & Yes & $\mathrm{No}$ \\
\cline { 2 - 3 } & $\mathrm{n}(\%)$ & $\mathrm{n}(\%)$ \\
\cline { 2 - 3 } Awareness of health interventions for malaria & & \\
\hline & $122(93.8)$ & $8(6.2)$ \\
\hline Knowledge of health interventions on malaria & & \\
\hline Insecticide-treated bed nets (ITNs & & $18(13.8)$ \\
\hline Indoor residual spraying (IRS) & $112(86.2)$ & $64(49.0)$ \\
\hline Intermittent preventive treatment (IPT) & $66(51.0)$ & $104(80.0)$ \\
\hline Artemisinin combination therapies (ACTs) & $26(20.0)$ & $75(57.7)$ \\
\hline
\end{tabular}

Table 2 shows that $93.8 \%$ of the respondents in the study area are aware of the interventions on malaria. It equally shows that they have a good knowledge of available interventions on malaria, with ITNs (86.2\%) predominating. This was distantly followed by IRS (51\%), ACTs (42.3\%) and IPT (20\%).

Table 3: Analysing regularity of health intervention messages from the media

\begin{tabular}{|c|c|c|c|c|}
\hline Variables & ITN & IRS & IPT & ACT \\
\hline & $\mathbf{n}(\%)$ & $\mathbf{n}(\%)$ & $\mathbf{n}(\%)$ & $\mathbf{n}(\%)$ \\
\hline Regularly & $185(47.6)$ & $104(26.7)$ & $76(19.5)$ & $78(20.1)$ \\
\hline Sometimes & $100(25.7)$ & $100(25.7)$ & $80(20.6)$ & $101(26.0)$ \\
\hline Rarely & $57(14.7)$ & $100(25.7)$ & $115(29.6)$ & $111(28.5)$ \\
\hline Never & $47(12.1)$ & $85(21.9)$ & $118(30.3)$ & $99(25.4)$ \\
\hline
\end{tabular}

Table 3 indicates that for specific health interventions, the percentage distribution of media friendly intervention was highest for ITN, with $47.6 \%$ agreeing that they regularly receive media message on this intervention. This is followed in descending order by IRS (26.7), ACTs (20.1\%) and IPT (19.5\%). The table also shows that IPT are not only rarely $(29.6 \%)$ aired and /or received, but also never (30.3\%) publicized or received. 
Table 4: Health/media intervention on malaria

\begin{tabular}{|c|c|c|c|c|}
\hline & ITN & IRS & IPT & ACTs \\
\hline Variables & $n(\%)$ & $n(\%)$ & $n(\%)$ & $\mathrm{n}(\%)$ \\
\hline Friend & $3(3.5)$ & $2(4.9)$ & $0(0.0)$ & $1(3.8)$ \\
\hline Radio & $32(37.2)$ & $13(31.7)$ & $2(8.3)$ & $7(26.9)$ \\
\hline Television & $31(36.0)$ & $11(26.8)$ & $6(25.0)$ & $9(34.6)$ \\
\hline Newspaper & $8(9.3)$ & $5(12.2)$ & $4(16.7)$ & $2(7.6)$ \\
\hline Magazine & $4(4.7)$ & $2(4.9)$ & $5(20.8)$ & $1(3.8)$ \\
\hline Church & $2(2.3)$ & $1(2.4)$ & $4(16.7)$ & $2(7.6)$ \\
\hline Association/Meetings & $2(2.3)$ & $1(2.4)$ & $2(8.3)$ & $4(15.4)$ \\
\hline Clinic & $4(4.7)$ & $6(14.6)$ & $1(4.2)$ & $0(0.0)$ \\
\hline \multirow[t]{2}{*}{ Total } & 86 & 41 & 24 & 26 \\
\hline & \multicolumn{4}{|c|}{$x^{2}=40.029 p=0.007$} \\
\hline
\end{tabular}

Table 4 shows that interventions on malaria were not independent of mass media interventions as it was statistically significant with $p$-value of 0.007 .

Table 5: Malaria awareness on the communication avenues

\begin{tabular}{|c|c|c|c|}
\hline Variables & No & Yes & Total \\
\hline Friend & $1(6.2)$ & $15(93.8)$ & 16 \\
\hline Radio & $2(1.9)$ & $102(98.1$ & 104 \\
\hline Television & $9(7.3)$ & $115(92.7)$ & 124 \\
\hline Newspaper & $3(5.9)$ & $48(94.1)$ & 51 \\
\hline Magazine & $3(9.7)$ & $28(90.3)$ & 31 \\
\hline Church & $3(15.0)$ & $17(85.0)$ & 20 \\
\hline Association/Meetings & $0(0.0)$ & $15(100.0)$ & 15 \\
\hline Clinic & $2(8.3)$ & $22(91.7)$ & 24 \\
\hline Others & $0(0.0)$ & $4(100.0)$ & 4 \\
\hline & \multicolumn{2}{|l}{} \\
\hline
\end{tabular}

Table 5 shows that the degree of awareness of malaria is independent on the communication avenues $(p=0.378)$.

\section{Discussion of Findings}

Research results revealed a predominance of female respondents in the research locations. This is understandable given the fact that they often constitute a higher percentage of the staff and /or attendants/domestic helpers to patients in the health facilities. The survey result also shows that the study population is highly educated. The implication is that a great proportion of the respondents attained up to at least the secondary school level of education. A knowledge of educational level of respondents is important because education broadens people's horizons, sharpens their understanding of issues and influences the acceptability or otherwise of healthcare interventions. The above claim is in tandem with the views of Nyunt et al (2015) in their study of Behaviour Change Communication (BCC) in Mynmar. They found out that there is a close relationship between higher education level and knowledge of malaria. Consequently, higher percentage of persons with good knowledge of malaria utilized health interventions. The study also sought to establish the relationship between health communication intervention, employment and educational status. It is argued that employment status and level of education influences access to communication interventions and ultimately, health interventions. Some scholars (Diala 2013; Martins 2011; Menaca et al 2013 and Pell et al 2011) have argued, and rightly too, that the social and cultural contexts in which health communication occurs are widely diverse ... For instance, Pell et al (2011) revealed that although a number of study sites linked mosquito bites with malaria, other factors were viewed in several others as playing a role. Such factors as lack of food during the fasting season and unhygienic practices in South-central Ethiopia; exposure to heat, poor hygiene and evil spirits in Southern Ghana; poverty, dirty water, poor hygiene and lack of blood in Central Uganda and humidity, rain and cold in Burkina Faso etc. were all linked to malaria infection. 
Therefore, messages must consider the variable levels of health literacy and education as well as other sociocultural and demographic factors that may influence effective communication when designing interventions (Grilli, Ramsay and Minozzi, 2002).

Furthermore, knowledge of a problem ultimately leads to solution. Findings in this study revealed that the awareness and knowledge-base on malaria interventions are high in the study locations. A number of factors account for this development. First, is the high level of educational attainment by the research subjects and second, the availability of variable media of communication which publicise the interventions. Different adverts on the interventions are run in a variety of ways in the media to encourage people to seek the interventions for their health benefits. Few examples include: advert on the need for pregnant women to register at health care centers near to them, in order to receive IPT, get tested and get free treated nets; advert on school pupils' absenteeism due to malaria, hence, the need for parents to provide treated nets for their children to sleep under without waiting for the government always. It also urges parents to register their children at health centres and get free ITNs; advert on arthmal, an anti-malarial drug that can cure malaria within three days, after which a doctor should be consulted if symptoms persists. Arthmal is a WHO approved ACT drug. These adverts run almost every day as commercials in the radio and majority of them are sponsored by State Ministry of Health and the Roll back malaria partners. Perhaps this is explainable against the fact that malaria, even though a household name in these parts, the interventions put in place to combat its scourge were mainly popularized via conventional media of communication.

It must be stressed that the high level of awareness of malaria in the study areas is not a function of the media alone, but a combination of many factors. Other channels such as patent medicine stores, clinics and interpersonal relationships among others, are contributory factors to this development. It must be noted, however, that although health intervention are not dependent on the mass media in some cases, this does not diminish the value of communication to health interventions, as communication is still valuable even for those that receive intervention messages chiefly through health facilities and other informal channels.

Findings also showed that malaria intervention programs in Enugu State are in tandem with international practices. In other words, there are variable interventions to address malaria malady in Nigeria, but whether or not these interventions are applied is another question. It must be noted however that malaria control and treatment in many countries, including Nigeria, are provided by the informal private sector (mainly shops) especially for the poorest (DFID and UK Aid, 2010). In Nigeria, for instance, ACTs are administered in pre-packaged, age-specific and color coded blister packs to buyers by trained patent medicine Vendors (PMVs) who are the closest source of medicines to treat malaria for a great majority of the people (DFID and UK Aid, 2010). Oral evidence revealed that some of these PMVs who availed themselves were trained for this purpose in Nigeria. Nevertheless, self-medication is a common practice.

Although the study population claimed to be aware of the interventions, further enquiry revealed that some people had limited knowledge on how to access the interventions and treatment regimens. Insecticide treated bed nets (ITNs), indoor residual spraying and ACTs are the more commonly known interventions. Nevertheless, oral evidence revealed that some people may know about a health intervention, but may refuse to utilise it because of the perceived inconvenience(s) of applying or using the intervention, hence the need for Behavioural Communication Change (BCC). BCC is widely considered as a vital tool for promoting improved health outcomes. It is known to have promoted attitudinal change and increased demand for health intervention (Nyunt et al). In malaria this commonly applies to the use of ITNs, which requires to be mounted on a prop before use. Being aware of the interventions presupposes that "knowledge about transmission of infection and how to protect oneself against it is...necessary" (Revised NTBCP, 2005), in any attempt to adopt appropriate remedial actions.

\section{Conclusion}

Greater flows of information are central to the success of the strategies to combat malaria. Health interventions on the illness are available, but they need to be vigorously communicated to ensure uptake of the interventions. Although the policy framework to address malaria in Nigeria have communication components, effort should be made to ensure that they are not only audience-specific, but also regularly projected to elicit the desired the impact. In fact, given the peculiarities of our community, other means of communication such as posters, billboards, association meetings, school counseling and workshops etc, should be equally employed.

\section{Recommendation}

1. There is need for multimedia and multifaceted approach in the communication of the illness. This entails that 
all key players including government/ policy makers, media practitioners, health care providers and the public be involved in the intervention programmes.

2. Government should provide the institutional backing for health communication intervention programmes to take place and be effective.

3. Health intervention messages should be framed in local languages and disseminated using community/area specific and user-friendly channels of communication in order not to disadvantage any group.

4. Associations/meetings are also vital means because they are more easily believed and understood by members. Group conviction they say, reinforces individual opinion towards accepting a line of action. Religious organizations and women associations, particularly in Igboland, served and still serve as potent means of information dissemination, including health information programmes.

\section{References}

Amajor, C. (2011).National Malaria Control Programme. [Online] Available: http://nmcpnigeria.org/(May 29, 2012).

Amodu, O. Adeyemo, A. Olumese, P. Gbadegesin, R. (1998). Intraleucocytic malaria pigment and clinical severity of malaria in children. Trans R Soc Trop Med Hyg. 92: 54-56.

Corcoran, N. (2007). Theories and models in communicating health messages. [Online] Available: www.corwin.com/upmdata/13975_Corcoran_Chapter_1.pdf(July 23, 2013).

DFID and UKaid Department for International Development and United Kingdom Aid (2010). Malaria: Burden and Interventions Evidence Overview. [Online] Available: r4d.dfid.gov.uk/Output/185824/Default.aspx (July 28, 2014).

Diala, C. (2013). Perceptions of intermittent preventive treatment of malaria in pregnancy Available: https://malariajournal.biomedcentral.com/articles/10.../1475-2875-12-34... (October 25, 2016).

Ebong, O. Nwauche, C. Ogbuehi, I. Chijioke-Nwauche, I. Ezirim, C. Umoh, R. Afia, A. Zara- kokpa, P.(2015). Is this Evidence of Success in Malaria Prevention and Control Measures? Greener Journal of Medical Sciences, 5(1):001-010, http://doi.org/10.15580/GJMS.2015.1.051114379 (October 24, 2016)

FRN (2009). Federal Republic of Nigeria Official Gazette. Abuja Vol. 96 No. $2^{\text {nd }}$ February.

FMOH (2008) "Malaria control in Nigeria: A strategy for behavior change communication 2008- 2010". Abuja: Roll Back Malaria Secretariat National Malaria Control Program

Department of Public Health Federal Ministry of Health Abuja, Nigeria.

Grilli, R. Ramsay, C. Minozzi, S. (2009). Mass media interventions: effects on health services utilisation. [Online] Available: http://www.thecochranelibrary.com (July 10, 2013).

Health Communication Strategies (2013). Module 1 Health Communication online course. [Online] Available: www.uniteforsight.org/health-communication-course/module 1 (July 18, 2013).

Jimoh, A. Sofola, O. Petu, A. Okorosobo, T. (2007). Quantifying the Economic Burden of Malaria in Nigeria Using the Willingness to Pay Approach. Cost Effectiveness and Resource Allocation. 5:6. doi:10.1186/1478-7547-5-6.

Martins, S. (2011). Oral health Behavioural and Social factors significantly impact oral health. J Public Health Dent. Winter 71(01) S2-S6 [Online] Available: https://www.ncbi

Maslove, D.Mnyusiwalla, A.Mills, E.McGowan, J.Attaran, A.Wilson, K. (2009). Barriers to the effective treatment and prevention of malaria in Africa: A systematic review of qualitative studies. [Online] Available: http://www.biomedcentral.com/1472698X/9/26(April 6, 2014).

MDG (2010). Nigerian Millennium Development Goals Report. [Online] Available: www.mdgs.gov.ng. (April 13, 2012).

Menaca, A. Pell, C. Manda-Taylor, L. Chatio, S. Afrah, N. Were, F. Hodgson, A. Ouma, P. Kalilani, L. Tagbor, H. Pool, R. (2013). Local illness concepts and their relevance for the prevention and control of malaria during pregnancy in Ghana, Kenya and Malawi: findings from a comparative qualitative study. [Online] Available: http://www.malarialjournal.com/content/12/1/257 (October 25, 2016).

Kelley, K. Clark, B. Brown, V. Sitzia, J. (2003). Good practice in the conduct and reporting of survey research. The int'l Journal for Quality in Health care [Online] Available: http://intqhc.oxfordjournals.org/content/15/3/261 (October 25, 2016).

NPC, NMCP, and ICF International. (2012). Nigeria Malaria Indicator Survey 2010. Abuja, Nigeria: National Population Commission (NPC) [Nigeria], National Malaria Control Programme (NMCP) [Nigeria], and ICF International. [Online] Available: measuredhs.com/pubs/pdf/MIS8/MIS8.pdf (May 11, 2012).

Nyunt, M. Aye, K. Kyaw, M. Wai, K. Oo, T. Than, A. Oo, H. Phway, H. Han, S. Htun, T. San, K. (2015). Evaluation of the behaviour change communication and community mobilization activities in Myanmar artemisinin resistance containment zones. Malaria Journal. DOI: 10.1186/s12936-015-1047-y

Ogundipe, S. and Obinna, C. (2010). Malaria:Killer at large. [Online]Available: http://www.vanguardngr.com/2010/09/malaria-killer-atlarge/(July 5, 2011).

Pell, C. Straus, L. Andrew, E. Meñaca, A. Pool, R. (2011). Social and Cultural Factors Affecting Uptake of Interventions for Malaria in Pregnancy in Africa: A Systematic Review of the Qualitative Research [Online] Available: http://journals.plos.org/plosone/article?id=10.1371/journal.pone.0022452 (October 25, 2016)

RNTCP (2005). A health communication strategy for Revised National Tuberculosis Control Programme (RNTCP). New Delhi: Central 
TB Division. Available: tbcindia.nic.in/.../Technical\%20\&\%200perational\%20guidelines\%20for\%2...(August 14, 2014) Sample size calculator (nd). THE SURVEY SYSTEM. Available: www.surveysystem.com/sscalc.htm (October 25, 2016). UNICEF/Nigeria/Gangale (2009). Partnering to roll back malaria in Nigeria's Bauchi State. Available: http://www.unicef.org/infobycountry/nigeria_49472(July 23, 2013).

USAID (2010). http://nigeria.usaid.gov/program/3 (July 6, 2012)

World Malaria Report (2015). Fact sheet. Available: http://www.who.int/malaria/media/world- malaria-report-2015/en/ (September 27, 2016). 